\title{
What Do We Know About Education in Colorectal Cancer Prevention?-Survey Among 1130 Medical Students
}

\author{
Lukasz Pietrzyk $^{1,2} \cdot$ Anna Torres $^{3} \cdot$ Marta Denisow-Pietrzyk $^{1} \cdot$ Kamil Torres $^{1}$
}

Published online: 26 December 2015

(C) The Author(s) 2015. This article is published with open access at Springerlink.com

\begin{abstract}
Colorectal cancer (CRC) is a global public health problem. The degree of knowledge on CRC among medical students, future physicians, brings essential implications for their patients. Therefore, to acquire information about students' knowledge on CRC, a questionnaire survey was conducted in Medical University of Lublin, Poland, with a representative sample of 1130 medical students (basic vs. clinical 552 vs. 578 male vs. female 442 vs. 688). The questionnaire was anonymous and designed in a four-section scheme (CRC risk factors, $\mathrm{CRC}$ prevention, $\mathrm{CRC}$ symptoms, CRC screening methods). There was a significant difference in the percentage of correct answers between basic and clinical level groups $(P=0.034)$. In general, clinical students had higher scores for their knowledge regarding CRC. Gender impacted the students' CRC knowledge to a lesser degree however, if the difference was revealed, female students were more aware about CRC issues $(P=0.045)$. We found several important deficits in students' knowledge on CRC. These findings should motivate the oncology education coordinator as well as our teachers to introduce innovations in education methods and training environments to enable students to gain necessary knowledge and acquire the skills and competencies that would help them to function as physicians.
\end{abstract}

Łukasz Pietrzyk

lukasz.pietrzyk@wp.pl

1 Department of Didactics and Medical Simulation, Medical University of Lublin, Jaczewskiego 4, 20-094 Lublin, Poland

2 Department of General and Minimally Invasive Surgery, 1st Military Clinical Hospital in Lublin, Lublin, Poland

3 Department of Human Anatomy, Medical University of Lublin, Lublin, Poland
Keywords Colorectal cancer · Oncology $\cdot$ Medical education $\cdot$ Medical student $\cdot$ Questionnaire

\section{Introduction}

Colorectal cancer (CRC), with nearly 1.4 million newly diagnosed cases in 2012, is the third most common neoplasm worldwide [1]. As in other countries, in Poland, an increasing trend in new CRC incidents is noted. For example, in 2010, 15,800 new cases have been diagnosed (8700 in males and 7100 in females); thus, an approximately fourfold increase has been evidenced since 1980 [2]. Heredity, gender, or ethnic as well as environmental factors (family status, lifestyle, smoking, low-fiber diet, overweight, and obesity-related syndromes) appear to be among the important factors of CRC risk, as reviewed by Pietrzyk et al. [3]. In Poland, the 5-year survival rate (below $25 \%$ ) is one of the lowest in the world [2]. The possible cause is due to a poor general health care system. Moreover, the National Colorectal Cancer Screening Program launched in October 2000 is deeply unpopular, presumably due to both the low health awareness of the Polish society and the inadequate education of physicians [4]. To decisively counteract this, the National Cancer Strategy (NCS) has been developed for 2015-2024 as an initiative of the Polish Society of Oncology, other scientific associations, and the Ministry of Health. The goals include a wide range of issues, i.e., coordination in defining and maintaining up to date all the diagnostic and therapeutic standards for all cancer types as well as training of health care professionals and promotion of scientific research. Building consciousness of welltrained multidisciplinary medical teams is an important tool in NCS, and the realization of prevention and CRC screening programs is a part of it. The CRC prevention strategy involves also improvement of the current medical education, starting 
from the academic degree [5]. It may sound unconvincing, but the development of the medical education in Eastern European countries, including Poland, has been affected by some historical determinants (the impact of the Cold War) and related to the heritage of communism, e.g., the lack of funds that hindered modern education methods. Since the 1990s, the transformation date, medical education is being constantly developed in Poland $[6,7]$. Medical education programs, including oncology education, were reviewed and accepted by the Ministry of Health. Integrated studies of medicine encompass basic courses and clinical courses. The oncology curriculum was based on the experience and recommendations of the European Association for Cancer Education (EACE) and the Union for International Cancer Control (UICC) [4]. At all medical universities, oncology is incorporated into the teaching courses in basic and clinical medicine programs with core lectures and seminars and the minimum number of classes devoted to oncology is $70[7,8]$. Academic teachers are supervised by an oncology education coordinator, who was appointed since 2010 [9]. The main hopes for improvement are the increase (i) in the number of integrated oncology units and (ii) in the number of academic teachers representing different branches of oncology [8]. However, despite the importance of colorectal cancer, the knowledge on CRC prevention issues is reported to be insufficient among medical students [8, 10]. Therefore, we designed a questionnaire survey for medical students to identify gaps in their knowledge about (i) CRC risk factors, (ii) $\mathrm{CRC}$ prevention, (iii) $\mathrm{CRC}$-associated symptoms, and (iv) CRC screening program in Poland. Information about knowledge deficit among medical students could help teachers to develop better teaching strategies and to prepare a more creative curriculum in order to improve students' learning outcomes.

\section{Methods}

\section{Study Population and Procedures}

A cross-sectional study was conducted between May and June 2015 among 1130 first- to sixth-year medical students of the Medical University of Lublin, Poland. The study population consisted of a basic-level group, which included first-, second-, and third-year medical students, whereas fourth-, fifth-, and sixth-year medical students were enrolled to a clinicallevel group (basic vs. clinical group 552 vs. 578 students). Among the total participants, 442 were males and $688 \mathrm{fe}$ males. Participants were randomly selected. Prior to the questionnaire distribution, all students selected to the survey were informed by the research team about the objectives of the study and on a voluntary basis accepted to participate in the survey. Participants completed a hard copy version of the questionnaire. The survey questions were developed basing on literature review and revised by a research team, including clinicians. The questionnaire was designed in four sections to provide information about medical students' knowledge of (I) CRC risk factors, (II) CRC prevention, (III) CRC-related symptoms, and (IV) CRC screening methods. The participants were asked to answer the questionnaire completely anonymously. Before the study has started, the questionnaires were distributed to a group of 15 students who were further excluded from the study population. The aim of this pilot study was to improve the questionnaire. The questionnaires were handed and collected in the seminar rooms by the technician staff to avoid the involvement and eventual influence of researchers on the process of data collection.

\section{Statistical Analysis}

Data was analyzed using descriptive statistics and presented as percentages. The chi-squared test was used to compare proportions of answers between groups of respondents: (i) basicvs. clinical-level students and (ii) male vs. female students. Differences were considered as statistically significant at $P<0.05$. Statistical analysis was performed using SPSS Version 16.0 (SPSS Inc., Chicago, IL, USA).

\section{Results}

One thousand and one hundred-thirty students answered the questionnaire. The respondents' mean age was 20.8 years (range 19-25 years) and $60.9 \%$ were females. The factor that influenced the students' knowledge was the course level, and there was a difference between different basic and clinical groups for most of the analyzed knowledge criteria. In general, clinical students had higher scores for their knowledge on colorectal cancer risk factors, prevention, and screening compared with basic-level students $(P=0.034)$. Gender impacted the students' CRC knowledge to a lesser degree. However, if there were significant differences between males and females, consciousness about CRC was more pronounced among women $(P=0.045)$.

Most (67-96.7\%) of the participants were aware of age as a factor increasing the risk of CRC; however, consciousness was significantly higher among the clinical-level group of students (Table 1).

A significant proportion of medical students (70-80\%) were informed that a fat-rich and low-fiber diet, substances produced during frying, ulcerative colitis, and a family history of the disease are among the important CRC risk factors (Table 2). In general, $88.4 \%$ of basic-level and $94.3 \%$ of clinical-level students, $91.4 \%$ on average have identified clearly that colon polyps are highly predictive of CRC. The participants tend to lack awareness that diabetes mellitus (only $15.3 \%$ of the total students), coffee drinking (23.1\% of the 
Table 1 The percentages of medical students who agreed with statements regarding age as a risk factor for colorectal cancer

\begin{tabular}{lccccccc}
\hline $\begin{array}{l}\text { Age group as } \\
\text { risk factor }\end{array}$ & $\begin{array}{l}\text { Basic } \\
\text { level }\end{array}$ & $\begin{array}{l}\text { Clinical } \\
\text { level }\end{array}$ & $P$ & Male & Female & $P$ & Total population \\
\hline $20-30$ & 1.0 & 0.1 & 0.042 & 0.5 & 0.6 & 0.031 & 1.1 \\
$30-40$ & 9.6 & 7.1 & & 6.5 & 10.2 & & 16.7 \\
$>50$ & 32.5 & 49.7 & & 30.4 & 51.8 & & 82.2 \\
\hline
\end{tabular}

$P$ value according to chi-squared test for the difference between basic and clinical groups and between male and female groups total students), and a carbohydrate-rich diet (36.8\% of the total students) may increase the chance of developing CRC. Only $53.4 \%$ of the total study group declared that Crohn's disease is associated with colon cancer. Obesity was identified among the risk factors by $66.8 \%$ of the participants.

A significant proportion of medical students was informed that physical activity ( $83.6 \%$ of total), avoidance of a high-fat diet $(83.5 \%)$, as well as a diet composed of fruits and vegetables $(83.5 \%)$ decrease in average the risk of CRC (Table 3). Interestingly, only $42.3 \%$ of the respondents recognized reduction of calorie intake among the specific prevention methods. The awareness that smoking cessation and control of alcohol consumption may prevent CRC disease was low, only 73.1 and $68.6 \%$ of the total participants, respectively.

Regarding the students' knowledge on colorectal cancer signs and symptoms, the majority of students properly indicated rectal bleeding $(79.9 \%)$ and fresh blood in stool $(80.7 \%)$ (Table 4). However, relatively few responders pointed out change of stool consistency $(52.5 \%)$, lack of appetite, weakness, and fatigue (41.8\%) among the meaningful CRC signs. Black stool was identified as a CRC-specific syndrome by $30.7 \%$ of the study groups. Interestingly, awareness of the link between black stool and CRC was significantly higher in the basic-level group of students.

Regardless of the academic level, medical students are correctly informed that a colorectal cancer screening program has been incorporated in Poland (Tables 5 and 6). However, their knowledge about the criteria for an individual selection to the program was very poor. Generally, $58.7 \%$ of the participants agreed age was among the inclusion criteria, but only $25.1 \%$ of the total students recognized correctly all inclusion criteria for recruitment to the CRC screening program. Majority of students $(87.3 \%)$ had knowledge that colonoscopy is offered as a free screening program to prevent colorectal cancer; clinical students were more conscious that colonoscopy is used as the primary screening modality in the national CRC prevention program $(81.1 \%$ basic vs. $93.3 \%$ clinical). There were 12.6-39.4\% of the total students who were false-positives about tools employed in the program. Significantly more clinical- than basic-level students (61.9 vs. $20.1 \%)$ were conscious where the screening program is available.
Table 2 The percentages of medical students who agreed with statements regarding the risk factors for colorectal cancer

\begin{tabular}{llllllll}
\hline Risk factors for colorectal cancer & $\begin{array}{c}\text { Basic } \\
\text { level }\end{array}$ & $\begin{array}{l}\text { Clinical } \\
\text { level }\end{array}$ & $P$ & Male & Female & $P$ & $\begin{array}{l}\text { Mean for total } \\
\text { population }\end{array}$ \\
\hline Fat-rich diet & 80.3 & 87.1 & 0.044 & 83.3 & 84.0 & $\mathrm{~ns}$ & 83.7 \\
Low-fiber diet & 76.8 & 93.4 & 0.032 & 82.5 & 87.0 & 0.042 & 85.3 \\
Carbohydrate-rich diet & 29.7 & 43.8 & 0.021 & 38.5 & 34.4 & $\mathrm{~ns}$ & 36.8 \\
Substances produced during frying & 77.2 & 82.4 & 0.036 & 80.4 & 79.5 & $\mathrm{~ns}$ & 79.9 \\
Coffee drinking & 29.2 & 17.4 & 0.012 & 24.5 & 22.4 & $\mathrm{~ns}$ & 23.1 \\
Smoking & 68.3 & 79.0 & 0.029 & 73.6 & 74.1 & $\mathrm{~ns}$ & 73.8 \\
Obesity & 71.9 & 61.9 & 0.023 & 64.4 & 68.4 & $\mathrm{~ns}$ & 66.8 \\
Crohn's disease & 48.4 & 58.3 & 0.018 & 52.1 & 54.4 & $\mathrm{~ns}$ & 53.4 \\
Ulcerative colitis & 84.6 & 78.4 & 0.026 & 81.1 & 81.9 & $\mathrm{~ns}$ & 81.6 \\
Colon polyps & 88.4 & 94.3 & 0.037 & 92.2 & 90.9 & $\mathrm{~ns}$ & 91.4 \\
Diabetes mellitus & 19.2 & 11.6 & 0.035 & 17.0 & 14.3 & $\mathrm{~ns}$ & 15.3 \\
Family history of cancer & 74.6 & 85.2 & 0.041 & 77.1 & 82.0 & 0.019 & 80.2 \\
\hline
\end{tabular}

$P$ value according to chi-squared test for the difference between basic and clinical groups and between male and female groups

$n s$ difference not significant 
Table 3 The percentages of medical students who agreed with statements regarding the prevention of colorectal cancer

\begin{tabular}{llllllll}
\hline Preventive factors & $\begin{array}{l}\text { Basic } \\
\text { level }\end{array}$ & $\begin{array}{l}\text { Clinical } \\
\text { level }\end{array}$ & $P$ & Male & Female & $P$ & $\begin{array}{l}\text { Mean for total } \\
\text { population }\end{array}$ \\
\hline $\begin{array}{l}\text { Increase the intensity and } \\
\text { regularity of physical activity }\end{array}$ & 61.6 & 65.3 & $\mathrm{~ns}$ & 59.4 & 66.1 & 0.042 & 63.6 \\
$\begin{array}{l}\text { Avoid high-fat diet } \\
\begin{array}{l}\text { Increase the consumption of } \\
\quad \text { ruits and vegetables }\end{array}\end{array}$ & 78.8 & 87.9 & 0.038 & 84.4 & 82.9 & $\mathrm{~ns}$ & 83.5 \\
$\begin{array}{l}\text { Reduce calorie intake } \\
\text { Avoid excess alcohol }\end{array}$ & 36.1 & 48.3 & 0.018 & 36.6 & 46.0 & 0.022 & 42.3 \\
Stop smoking & 66.8 & 67.6 & $\mathrm{~ns}$ & 68.6 & 65.7 & $\mathrm{~ns}$ & 67.2 \\
\hline
\end{tabular}

$P$ value according to chi-squared test for the difference between basic and clinical groups and between male and female groups

$n s$ difference not significant

\section{Discussion}

Emphasis on medical education is an integral part of the strategy for the decrease of CRC incidents [4]. Therefore, we conducted the survey in order to evaluate the awareness of our medical students on CRC risk factors, prevention, symptoms, and related issues of colorectal cancer diagnosis and national screening modalities. The present study acquired information that would guide educators about knowledge deficit among medical students. In Polish universities, a uniform curriculum in academic oncology has been introduced since 2010 [7, 9]. Therefore, despite the fact that our study is limited to a single university, it has a relatively large sample size and we expect the study will serve the academic body to keep and/or improve medical education standards to meet the public interest in respect of prevention and quick diagnosis of CRC.

We found that the knowledge regarding CRC increased in the clinical years, as evidenced by the increase in correct answers between basic and clinical levels. This suggests that the environment to which our students are exposed is relevant for development of knowledge. This also indicates that our clinical classes (observation of clinical practices, contact with patients) are particularly important in developing CRC knowledge. Many studies reported that practical classes are more effective for medical education and students' achievements than theoretical classes [10-13].

Regardless of the academic levels, our results demonstrated gaps in different aspects of CRC knowledge among students. These results are in agreement with published literature regarding cancer education among medical students. Multiple studies have revealed that cancer education is inadequate, fragmented, and poorly coordinated at medical universities [13-15]. With this in mind, we have to consider which elements of our education programs clearly need standards improvement in terms of CRC risk factors, prevention, as well as symptoms and national screening programs.

The first part of the questionnaire was developed to evaluate knowledge on CRC risk factors, and the second part
Table 4 The percentages of medical students who agreed with statements regarding the symptoms of colorectal cancer

\begin{tabular}{llllllll}
\hline Symptoms of colorectal cancer & $\begin{array}{c}\text { Basic } \\
\text { level }\end{array}$ & $\begin{array}{l}\text { Clinical } \\
\text { level }\end{array}$ & $P$ & Male & Female & $P$ & $\begin{array}{l}\text { Mean for total } \\
\text { population }\end{array}$ \\
\hline Rectal bleeding & 77.3 & 82.4 & 0.037 & 74.8 & 83.0 & 0.039 & 79.9 \\
Fresh blood in stool & 75.5 & 85.7 & 0.029 & 80.0 & 81.1 & ns & 80.6 \\
Black stool & 33.9 & 20.0 & 0.035 & 24.2 & 30.1 & 0.022 & 27.0 \\
$\quad \begin{array}{l}\text { Change in bowel habits, including } \\
\quad \text { diarrhea and constipation }\end{array}$ & 54.8 & 70.5 & 0.018 & 57.3 & 66.4 & 0.028 & 63.0 \\
Change of consistency of stool & 42.5 & 61.9 & 0.002 & 50.2 & 53.9 & $\mathrm{~ns}$ & 52.5 \\
$\begin{array}{l}\text { Persistent abdominal discomfort } \\
\text { Unexplained weight loss }\end{array}$ & 68.8 & 60.7 & 0.036 & 65.8 & 63.8 & $\mathrm{~ns}$ & 64.6 \\
$\quad$ Lack of appetite, weakness, and & 35.1 & 87.1 & 0.004 & 70.8 & 75.7 & $\mathrm{~ns}$ & 73.9 \\
$\quad$ fatigue & & & 0.041 & 41.5 & 42.0 & $\mathrm{~ns}$ & 41.8 \\
\hline
\end{tabular}

$P$ value according to chi-squared test for the difference between basic and clinical groups and between male and female groups

$n s$ difference not significant 
Table 5 The percentages of medical students who agreed with statements regarding the inclusion criteria for colorectal cancer screening programs in Poland

\begin{tabular}{lccccccc}
\hline Criteria & $\begin{array}{c}\text { Basic } \\
\text { level }\end{array}$ & $\begin{array}{l}\text { Clinical } \\
\text { level }\end{array}$ & $P$ & Male & Female & $P$ & Mean \\
\hline $\begin{array}{l}\text { People aged 50 to 66 years with no } \\
\quad \text { clinical suspicion of CRC }\end{array}$ & 39.9 & 76.7 & 0.003 & 52.7 & 62.4 & 0.026 & 58.7 \\
$\begin{array}{l}\text { People aged 40 to 70 years with no } \\
\text { clinical suspicion of CRC }\end{array}$ & 24.6 & 7.6 & 0.002 & 18.2 & 14.5 & ns & 15.9 \\
$\begin{array}{l}\text { People aged 40-49 with a family } \\
\text { cancer history }\end{array}$ & 32.4 & 46.7 & 0.023 & 31.4 & 44.6 & 0.037 & 39.7 \\
$\begin{array}{l}\text { People aged 50 to 66 years (for people with } \\
\text { a family cancer history, age limit was } \\
\quad<40 \text { years) with no clinical symptoms } \\
\text { of CRC }\end{array}$ & 13.3 & 36.2 & 0.028 & 18.7 & 29.0 & 0.014 & 25.1 \\
\begin{tabular}{l} 
There is no such program in Poland \\
\hline
\end{tabular} & 5.6 & 2.8 & 0.043 & 7.6 & 2.1 & 0.041 & 4.2 \\
\hline
\end{tabular}

$P$ value according to chi-squared test for the difference between basic and clinical groups and between male and female groups

$n s$ difference not significant focused on CRC prevention methods. We expected all students to achieve at least $80 \%$ of the scores in the identification of CRC risk and prevention factors. High scores were achieved in identifying some risk factors for CRC; these included a fat-rich diet, a low-fiber diet, tobacco use, and a family history of CRC. However, low scores were observed when identifying risk factors such as a carbohydrate-rich diet, coffee drinking, or diabetes mellitus. The students' knowledge about the potential obesity contribution to the prognosis of colorectal cancer is also inadequate; almost $36 \%$ of the students did not link obesity with an increased incidence of CRC. The WHO formally recognized obesity as a global epidemic; therefore, CRC prevention strategies will require providing patients with sufficient information on the relationship between obesity and the risk of CRC development [3, 16]. Therefore, our students' awareness of the obesity-CRC relationship needs to be rapidly changed. It has been suggested that cancer prevention education in medical schools is essential for medical students, tomorrow's physicians [14]. Physicians play a crucial role in promoting healthier lifestyles, advise how to prevent disease, and can considerably impact on the patients' attitudes towards CRC [17]. Medical students' sufficient knowledge concerning protective topics might lead to a prospective increase of social consciousness that CRC development might be stopped by patients' own actions regarding lifestyle. In this respect, students' knowledge about potentially modifiable factors (e.g., obesity, drinking alcohol, smoking) is fundamental and should be sufficiently monitored. At Polish medical universities, efforts are being made to give information about the social factors in cancer etiology since the first year of medical education [9]; therefore, attempts are needed to improve training methods in oncologyrelated classes.

In our study, a relatively low percentage of students was conscious that a reduction in daily caloric intake and avoidance of alcohol might significantly reduce CRC risk. Highcalorie foods as well as alcohol consumption are a part of "westernization" of lifestyle [16]. Harmful or hazardous consumption of alcohol beverages has been identified as being a problem among medical students [18-20]. It is possible that the students who participated in our survey treat fatty food and alcohol consumption as integral parts of life and do not
Table 6 The percentages of medical students who agreed with statements regarding the methods used in screening programs for colorectal cancer in Poland

\begin{tabular}{lcllllll}
\hline Screening method & $\begin{array}{l}\text { Basic } \\
\text { level }\end{array}$ & $\begin{array}{l}\text { Clinical } \\
\text { level }\end{array}$ & $P$ & Male & Female & $P$ & $\begin{array}{l}\text { Mean for total } \\
\text { population }\end{array}$ \\
\hline Colonoscopy & 81.1 & 93.3 & 0.031 & 82.3 & 90.3 & 0.039 & 87.3 \\
Blood CEA level & 20.0 & 10.2 & 0.038 & 12.9 & 18.4 & 0.041 & 15.0 \\
Fecal occult blood test & 38.8 & 39.8 & $\mathrm{~ns}$ & 41.8 & 37.9 & $\mathrm{~ns}$ & 39.4 \\
Digital rectal examination & 41.9 & 34.8 & 0.042 & 37.6 & 38.8 & $\mathrm{~ns}$ & 38.3 \\
$\begin{array}{l}\text { Rectoscopy } \\
\text { There is no such program } \\
\text { in Poland }\end{array}$ & 13.8 & 11.4 & $\mathrm{~ns}$ & 14.9 & 11.2 & $\mathrm{~ns}$ & 12.6 \\
\hline
\end{tabular}

$P$ value according to the chi-squared test for the difference between basic and clinical groups and between male and female groups

$n s$ difference not significant 
recognize them as factors that cause health problems. A poor level of knowledge towards the relationship between lifestyle and colorectal cancer was reported among medical students in Mexico [12] or in Malaysia [21]. Deficits in knowledge were also reported among medical students in the USA [17]. Therefore, preventive medicine was implemented in several universities and it is believed that education regarding healthy lifestyle habits present in medical curricula would be an advantage and would help physicians to keep their patients healthy $[10,17]$.

We found it very disturbing that almost $6 \%$ of our clinicallevel students and almost $12 \%$ of basic-level students were not aware that colon polyps are among the potential risks of colon cancer. The students' awareness of easy to detect and remove non-cancerous polyp abnormalities before they have the chance to turn into cancer [3, 4] should not be ignored. Medical students as well as physicians may have a great impact on patients' motivation to remove polyps, reducing the risk of dying from colorectal cancer [11-13]. Knowledge on preventive behaviors may also improve attitude, disbelief, and misunderstanding and consequently improve healthy living and enhance screening practices.

The third part of our questionnaire was designed to assess the students' knowledge in relation to CRC symptoms. The present study revealed insufficient knowledge towards colorectal signs. For example, very low scores were observed in relation to black stool and changes of stool consistency. The gaps in knowledge about CRC-specific symptoms were reported for Greek and American students [15, 22]. Teaching the disease symptoms is an integral part of medical education, and emphasis on cancer symptoms in the medical curriculum possibly would result in early cancer detection and in consequence could hinder the cancer disease [22, 23]. Several authors have pointed out that fragmented knowledge on cancer symptoms is related to a low level of medical students' exposure to patients with cancer $[9,10,14]$. In Poland, attempts are made to increase the knowledge of medical students regarding oncology by launching, by the Polish government, the "National Program for Combating Neoplastic Diseases" incorporated since 2005. One of the advantages of the program is the increase of clinical classes in oncology units at patients' beds [9]. However, our survey indicated that we need to develop an algorithm to achieve students' knowledge efficiency.

The fourth part of the questionnaire was designated to assess students' attitude towards CRC screening methods. Fatalistic attitudes have been identified among students for screening methods in the USA [14]. The students' and physicians' approach to CRC screening modalities, especially colonoscopy, may have a great impact on the patients' opinion and motivation to undergo colonoscopy [15]. It is encouraging that a remarkably high percentage (81-93\%) of our students reported colonoscopy among the screening methods used in national CRC prevention programs. However, in terms of access to the program and screening tests for CRC, a high proportion of participants were not able to indicate how to be involved in the program. Also, our students were not aware of the selection criteria for CRC screening programs.

The correct response rate among female students was higher than the response among males. In literature, numerous gender differences are discussed regarding work organization and types of care rendered by male and female medical students and doctors [24]. The female gender is usually associated with a stronger intention towards knowledge improvement as well as in continuing medical education [25].

Undoubtedly, all medical students have to gain essential knowledge about CRC. However, the most important questions are what should be learned at the basic and clinical levels and what are the most efficient teaching methods $[9,26]$. Most likely, we need to develop the instrument for improvement in curricular modules in subsequent years to raise the awareness of CRC among medical students. There are many debates in the medical education literature regarding how to pass the knowledge best and assess students' skills and competencies, and it is accepted that improving the quality of assessments in medical programs is beneficial to students and their patients $[11-17,26,27]$. It is certainly the coordinator of academic medical programs who should be responsible for filling gaps in the program. The primary objective of medical education is to provide basic knowledge necessary to build on during postgraduate training. However, the essential problem in an academic medical education in Poland is that existing oncology units are seldom integrated [9]. We assume that the undergraduate curriculum should include more oncology-related courses with emphasis on preventive medicine and hands-on courses that would allow students to familiarize symptoms and screening tools.

Despite the weakness and gaps in our students' knowledge, we look forward to the future with a lot of optimism. We hope the survey will enable us to give a new momentum to raise educational scores. Several universities have modified their undergraduate programs in oncology and teaching methods, introducing up-to-date methods, including computer learning and simulation techniques [13, 14, 17, 26, 27]. Our university is in a group of Polish medical universities which improve undergraduate oncology education [9].

To summarize, improving the quality of oncological education is a long-term process. Our data would suggest that there remain areas that need to be addressed and that there are several implications for future curriculum development in regard to colorectal cancer education particularly on risk factors, prevention, symptoms, and screening methods. 
Acknowledgments We would like to thank Michał Hader, a third-year medical student, who helped us during the questionnaire survey and computer data preparation.

\section{Compliance with Ethical Standards}

Conflict of Interest The authors declare that they have no competing interests.

Open Access This article is distributed under the terms of the Creative Commons Attribution 4.0 International License (http:// creativecommons.org/licenses/by/4.0/), which permits unrestricted use, distribution, and reproduction in any medium, provided you give appropriate credit to the original author(s) and the source, provide a link to the Creative Commons license, and indicate if changes were made.

\section{References}

1. GLOBOCAN 2012 Estimated cancer incidence, mortality and prevalence worldwide in 2012. http://globocan.iarc.fr/Pages/ fact_ sheets_cancer.aspx (accessed 10.08. 2015)

2. Wojciechowska U, Didkowska J (2013) Zachorowania i zgony na nowotwory złośliwe w Polsce. Krajowy Rejestr Nowotworów, Centrum Onkologii - Instytut Marii Skłodowskiej - Curie. http:// onkologia.org.p1/raporty/ (accessed 20.08.2015)

3. Pietrzyk L, Torres A, Maciejewski R, Torres K (2015) Obesity and obese-related chronic low-grade inflammation in promotion of colorectal cancer development. Asian Pac J Cancer Prev 16:41614168. doi:10.7314/APJCP.2015.16.10.4161

4. National Program for Combating Neoplastic Diseases. Ministry of Health Republic of Poland (2005) http://www.mz.gov.pl/zdrowie-iprofilaktyka/narodowy-program-zdrowia (accessed 22.08.2015)

5. Mattes MD, Patel KR, Burt LM, Hirsch AE (2015) A nationwide medical student assessment of oncology education. J Cancer Educ. 2015 Jul 1

6. Wozniak L (1993) The programme of undergraduate cancer education of the Lódz school of medicine (Poland). J Cancer Educ 8:11-14

7. Matkowski R, Szelachowska J, Szewczyk K, Staszek U, Kornafel J (2010) Evaluation of changes in undergraduate oncology teaching at Polish medical universities introduced under the National Program Against Cancer Diseases. In the program and abstract booklet of the European Association for Cancer Education 23rd Annual Scientific Meeting: 23-25 June 2010; Enschede, Netherlands: p. 48 item 24

8. Kornafel J, Matkowski R (2008) Ujednolicony program nauczania onkologii w polskich uczelniach medycznych. Zesz NaukWielkopol Centr Onkol 5:66-67

9. Matkowski R, Szelachowska J, Szewczyk K, Staszek-Szewczyk U, Kornafel J (2014) Improvements in undergraduate oncology education introduced at Polish Medical Universities between 2004 and 2010 under Poland's "National Program for Combating Neoplastic Diseases”. J Cancer Educ 29:428-433. doi:10.1007/s13187-0140633-y

10. Agarwal A, Shah A, Byler S, Hirsch AE (2015) Cultivating interest in oncology through a medical student oncology society. J Cancer Educ. 2015 Sep 5

11. Lewis B, Rakinic J, Hassan I (2011) Knowledge and attitudes regarding colorectal cancer screening among medical students: a tale of two schools. J Cancer Educ 26:147-152. doi:10.1007/s13187010-0161-3

12. Villarreal-Garza C, García-Aceituno L, Villa AR et al (2010) Knowledge about cancer screening among medical students and internal medicine residents in Mexico City. J Cancer Educ 25: 624-631

13. Hauer KE, Wilkerson L, Teherani A (2008) The relationship between medical students' knowledge, confidence, experience, and skills related to colorectal cancer screening. J Cancer Educ 23: 209-213

14. Chamberlain RM, Bakemeier RF, Gallagher RE, Kupchella CE, O’Donnell JF, Parker JA, Hill GH, Michael Brooks C (1992) Cancer prevention education in United States medical schools. Cancer education survey II: cancer education in United States medical schools. J Cancer Educ 7:105-114

15. Papanikolaou IS, Sioulas AD, Kalimeris S, Papatheodosiou P, Karabinis I, Agelopoulou O, Beintaris I, Polymeros D, Dimitriadis G, Triantafyllou K (2012) Awareness and attitudes of Greek medical students on colorectal cancer screening. World J Gastrointest Endosc 4:513-517. doi:10.4253/wjge.v4.i11.513

16. Winkels RM, Heine Broring RC, van Zutphen M et al (2014) The COLON study: colorectal cancer: longitudinal, observational study on nutritional and lifestyle factors that may influence colorectal tumor recurrence, survival and quality of life. BMC Cancer 14:374

17. Boehler M, Advani V, Schwind CJ, Wietfeldt ED, Becker Y, Lewis B, Rakinic J, Hassan I (2011) Knowledge and attitudes regarding colorectal cancer screening among medical students: a tale of two schools. J Cancer Educ 26:147-152. doi:10.1007/s13187-0100161-3

18. European Commission. Special Eurobarometer 272 (2007) Attitudes towards alcohol. http://ec.europa.eu/public_opinion/ archives/ebs/ebs 272b_en.pdf (accessed 2.09. 2015)

19. Puig-Nolasco A, Cortaza-Ramirez L, Pillon SC (2011) Alcohol use among Mexican medical students. Rev Lat Am Enfermagem 19: 714-721

20. Rustagi N, Taneja D, Mishra P, Ingle G (2011) Cardiovascular risk behavior among students of a medical college in Delhi. Indian $\mathrm{J}$ Community Med 36:51-53

21. Al-Naggar RA, Bobryshev YV (2013) Knowledge of colorectal cancer screening among young Malaysians. Asian Pac J Cancer Prev 14(3):1969-1974. doi:10.7314/APJCP.2013.14.3.1969

22. Lee M, Wilkereson L, Harrity S, Hodgson CS (2006) Differences in cancer prevention knowledge and experience among medical students at three institutions over time. J Cancer Educ 21(4):223-229

23. Geller AC, Prout M, Miller DR, Siegel B, Sun T, Ockene J, Koh HK (2002) Evaluation of a cancer prevention and detection curriculum for medical students. Prev Med 35(1):78-86

24. Hojat M, Gonnella JS, Xu G (1995) Gender comparisons of young physicians' perceptions of their medical education, professional life, and practice: a follow-up study of Jefferson Medical College graduates. Acad Med 70(4):305-312

25. Casanova L, Ringa V, Bloy G, Falcoff H, Rigal L (2015) Factors associated with GPs' knowledge of their patients' socio-economic circumstances: a multilevel analysis. Fam Pract. doi:10.1093/ fampra/cmv068

26. Van der Vleuten CPM, Schuwirth LWT (2005) Assessing professional competence: from methods to programmes. Med Educ 39: 309-317

27. Mineikyte R, Janulionis E, Liutkevciute-Navickiene J, Atkocius V (2014) Cancer education in Lithuania. Ecancer 8:487 DOI: 103332/ ecancer.2014.487 